\title{
Low QRS Voltage by ECG Finding
}

National Cancer Institute

\section{Source}

National Cancer Institute. Low QRS Voltage by ECG Finding. NCI Thesaurus. Code C71078.

An electrocardiog raphic finding of a QRS amplitude less than or equal to $0.5 \mathrm{mV}$ in the limb leads or QRS amplitude less than or equal to $1 \mathrm{mV}$ in the precordial leads. (CDISC) 